\title{
Manufacturability and Surface Characterisation of Polymeric Microfluidic Devices for Bio-medical Applications
}

\section{Yugandhar Arcot}

Indian Institute of Technology

Samuel G.L ( $\sim$ samuelgl@iitm.ac.in )

Indian Institute of Technology https://orcid.org/0000-0003-3558-8425

Lingxue Kong

Deakin University

\section{Research Article}

Keywords: Mechanical Micromachining, Microfluidics, Polymers, Surface roughness, Surface energy

Posted Date: November 8th, 2021

DOI: https://doi.org/10.21203/rs.3.rs-937595/v1

License: (c) (i) This work is licensed under a Creative Commons Attribution 4.0 International License.

Read Full License 


\title{
Manufacturability and Surface characterisation of polymeric microfluidic devices for biomedical applications
}

\author{
Yugandhar $\operatorname{Arcot}^{1,2}$, G.L. Samuel ${ }^{1, *}$, and Lingxue Kong ${ }^{2}$ \\ 1,* Manufacturing Engineering Section, Department of Mechanical Engineering, Indian Institute of \\ Technology, Chennai - 600 036, INDIA \\ ${ }^{2}$ Deakin University, Geelong, Institute for Frontier Materials, VIC 3216, AUSTRALIA \\ *Corresponding author: samuelgl@iitm.ac.in
}

\begin{abstract}
:
Microfluidic devices fabricated through mechanical micromachining techniques have already been reported to be highly economical when compared to other techniques. Direct mechanical machining processes are generally classified as a one-step manufacturing process, having the advantages of rapid prototyping and batch production. Though there are advancements in ultraprecision machining techniques, the real challenge of direct machining polymeric microfluidic channels is the occurrence of poor surface integrity owing to the change in mechanical as well as viscoelastic properties. This forms the key objective of the present research work, where the major emphasis has been given to understand the applicability of micro-milling techniques in fabricating microfluidic devices, especially for bio-applications. In this research, the mechanical micro-milling technique was used to create microscale channels on polymethylmethacrylate (PMMA) and polycarbonate (PC) materials; wherein the process capability was mainly assessed based on the surface characteristics of the micro features. Furthermore, for the quantitative analysis, a comparative study was also performed by measuring the surfaces roughness and surface energy of the microchannels made by various fabrication routes such as hot embossing and lithography. The experimental results indicate that the micro-milling of PMMA is the preferable choice for fabricating microfluidic devices when compared to PC. Also, for showing the manufacturability of the mechanical micromachining technique, microfluidic channels with serpentine channels were machined with a depth and width of $50 \mu \mathrm{m}$ and $200 \mu \mathrm{m}$ respectively. The applicability of the fabricated microfluidic devices was further validated by evaluating the functioning of these devices for blood cell separation at different dilution rates.
\end{abstract}

Keywords: Mechanical Micromachining, Microfluidics, Polymers, Surface roughness, Surface energy 


\section{Introduction:}

Mechanical micromachining on polymers is widely used in research laboratories for fabricating microfluidic devices mostly for biomedical applications. Owing to the capability of the applications and commercial advantages, the development of manufacturing for batch and mass production is crucial[1],[2]. Thermoplastics are the most widely used materials suitable for mass production and are biocompatible[3] Currently, polydimethylsiloxane (PDMS) lithography is a widely used method for fabricating microfluidic devices. Manufacturing methods like injection molding [4], hot embossing[5] were successfully employed to fabricate microstructures. These methods are more suitable for mass production and not at the prototyping stage of a device. Mould masters using mechanical micro-milling were fabricated for the largerscale fabrication of microfluidic devices, and PDMS was used as a substrate material for building the device[6],[7],[8]. Similar to lithography methods, this process involves large production times and is therefore not suitable for prototyping. Low cost of working materials, ease of fabrication allows prototyping, and patient-specific devices to be fabricated within very little time. For this, direct machining techniques like mechanical micromachining will be more suitable. Mechanical machining changes the surface characteristics and other properties like optical transparency, biocompatibility and depends upon the parameters used during machining[9],[10]. In this study, the effects of the end-milling on surface characteristics like roughness, surface energy, and burr formation on PMMA and PC wafers are investigated. The machined surfaces on the wafers are obtained by varying feed rate and depth-of-cut at a constant speed of 20,000 rpm using a micro-milling tool developed in-house[11],[12]. Surfaces obtained from other fabrication methods like $3 \mathrm{~d}$ printing, hot embossing, and photo-lithography are compared with the machined surfaces for surface energy. Furthermore, to evaluate mechanical micro-milling, a microfluidic device with serpentine channels is fabricated and investigated for blood cell separation. 


\subsection{Mechanical Micromachining:}

Mechanical micromachining has largely been used to machine metallic materials and theories were developed to achieve better quality developed when compared to polymeric materials[13],[14]. Many numerical models related to the analysis of mechanical micro-milling were developed. Due to the higher stress variations in micro tools the surface quality of the obtained surfaces is affected. As the uncut chip thickness is close to the cutting-edge radius, ploughing action is more dominant than cutting action. These actions lead to the formation of burrs and side flow of the deformed material increasing the surface roughness[15]. In the previous studies on polymers, the roughness obtained on PMMA was between $0.13 \mu \mathrm{m}$ to $0.3 \mu \mathrm{m}[16]$ with spindle speed and depth-of-cut have the least and largest impact on the surface roughness $(\mathrm{Ra})$. In a similar study, a single edge diamond tool with a diameter $<50 \mu \mathrm{m}$ was used to machine PMMA and achieved dimensions around $50 \mu \mathrm{m}$ with surface roughness $\left(\mathrm{R}_{\mathrm{a}}\right)<60 \mathrm{~nm}[17]$. Investigations performed on PMMA, Polyether ether ketone (PEEK) and Polyimide (PI) materials showed that as the spindle speed and tool diameter increased the milling temperature was increased[18]. As the temperatures increase polymer materials undergo three distinct regimes (glassy, viscoelastic, and rubbery), and fracture mechanism changes from brittle to ductile. At lower temperatures when the fractures are brittle, the burr formation was less compared to machining at higher temperatures. The burr formation of PMMA was relatively less when compared to PEEK and PI. Surface quality was affected when the machining was taking place in the viscoelastic regime due to the sintering of chips to the channels. For an ideal microfluidic device, the least surface roughness with no burrs is desirable as they introduce unknown micro-hydrodynamic forces developed during the fluid flow[19]. Burrs are undesirable extended surfaces over the edges of the workpiece which are caused to the plastic deformation induced by shear strain [20],[21]. This burr formation is unavoidable as it may introduce undesirable forces during flow and affect the bonding of the devices causing leakages.

\subsection{Effect of machining on thermoplastic surfaces:}

Process parameters like compressive forces, shear forces, and frictional heating affect the surface roughness of polymer machining[22]. If the machining is taking place below the glass 
transition temperature ( $\mathrm{Tg})$ the material will behave as a solid and either ductile or brittle fracture may be observed. As a result of the frictional heating during machining, the viscoelastic property of the polymer comes into effect. This viscoelastic property of polymers results in machining to take place in a zone that is in neither plastic nor elastic state termed as an intermittent rubbery zone. The arrival of the polymeric material to this rubbery zone depends upon the glass transition temperature of the material. During machining in this rubbery zone, forces from the tool constantly act on the polymer chains in a fluid state and cause them to rise along with the tool as shown in figure 1. This is called as Weissenberg effect or climbing effect of polymers and depends upon the molecular weight of the polymers. In this study, PMMA and PC materials with different Tg's will be compared to each other for achieving the least surface roughness during machining. This will help to decide the most suitable material within the specified range of parameters.

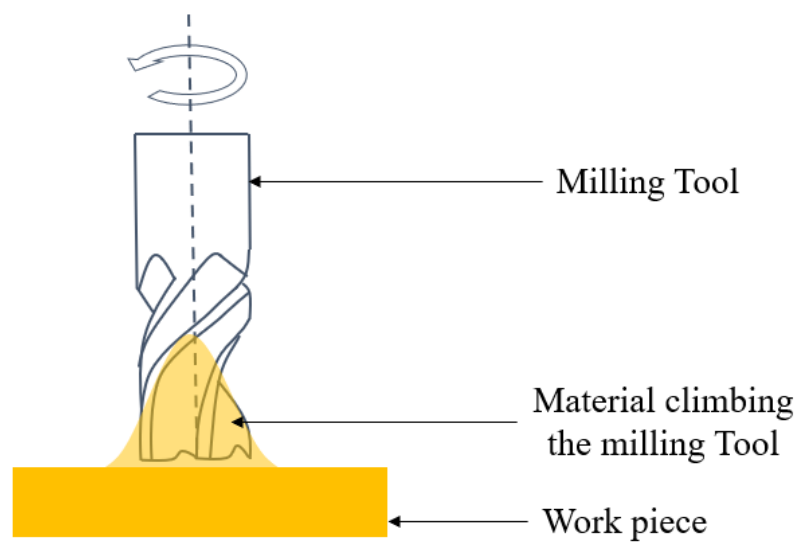

Figure 1: Schematic showing Weissenberg effect - Polymer material climbing the milling tool while machining

The surface roughness affects the wettability of the surface as the ratio of surface roughness to the dimension of microfluidics is generally very large[23]. A rough surface causes a pressure drop, alters wettability which increases with roughness[24],[25]. Surface roughness is the irregularities of peaks and valleys on the surface inherited by the fabrication process itself and is measured using surface roughness parameters. Average Roughness (Ra) is one such parameter used in measuring surface roughness. It is defined as the arithmetic average of the absolute values of the profile heights over the evaluation length. The machined surface could become 
either hydrophobic or hydrophilic due to the presence of the peaks and valleys which are imparted during machining as shown in figure $2 \mathrm{a}$. These peaks and valleys introduce Wenzel or Cassie- Baxter effects where the ability of the liquid droplets to penetrate valleys of the surface

(a)

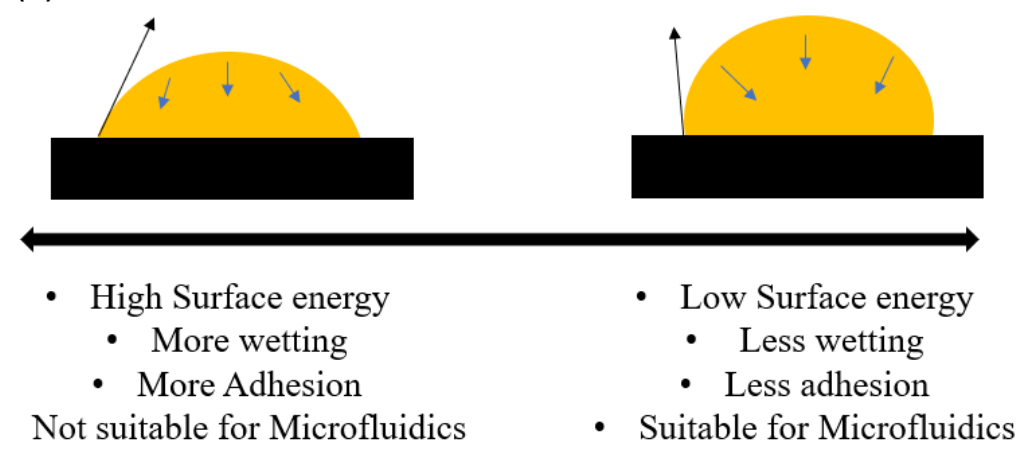

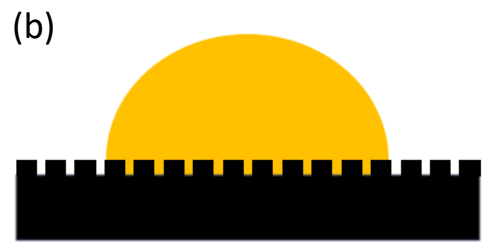

Wenzel effect

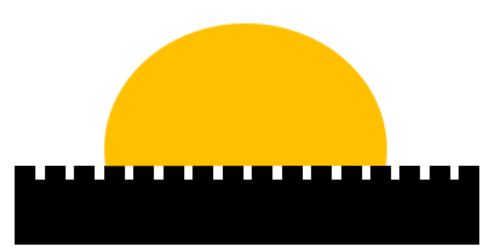

Cassie- Baxter effect

Figure 2: a) Schematic showing contact angles and surface energy on the surfaces b) Schematic showing the effect of air gaps in the peaks and valleys of rough surfaces on liquid droplets after machining

are altered and in turn change the wettability of the surface as shown in figure $2 b$. Surface energy is a quantitative measurement for evaluating the quality of the surface where lower surface energy implies higher contact angle and lower wetting. It is a relative measurement of the energy and is caused due to surface atoms having an incomplete, unbalanced set of interactions. Therefore, the surface energy of the machined surfaces is compared with that of surfaces fabricated using various methods.

\subsection{Microfluidic devices - Biomedical Application:}

Generally, microfluidic devices using the Inertial focusing phenomenon[26] for particle separation have channels profile with different geometries like spiral[27], serpentine[28], and with varying cross sections[29],[30]. Devices with parallel channels were reported for achieving high throughput $(240 \mathrm{ml} / \mathrm{h})$ while achieving separation efficiency of $80 \%$ of pathogenic bacteria from blood flow[31]. Another prominent technique for passive manipulation of fluids is 
Deterministic Lateral Displacement (DLD) separation where arrays of pillars are used for deviating particles from the stream lines[32],[33],[34]. In these devices, particles are influenced by fluidic forces and obstacles posed by pillars. The gaps between these pillars are required for the separation range in micrometers $(10-20 \mu \mathrm{m})$ in DLD devices, but inertial focusing devices have relatively large dimensions $(50-650 \mu \mathrm{m})$. This makes mechanical micromachining more suitable for fabricating microfluidic devices that use inertial focussing for particle separation. Considering parallelizability and dimensions for manufacturability using mechanical micromilling, a microfluidic device with serpentine channels suitable for inertial focussing is fabricated and investigated for blood cell separation.

\section{Device Fabrication - Design and Force analysis}

As mechanical micro-milling is the choice for fabricating microfluidic devices, the design of the microfluidic devices depends on the size of the tools, which is the caveat during machining. The microfluidic devices generally consist of straight and curved fluidic channels, pillars, inlets, and outlets for collecting and transferring the fluids which vary from millimeters to nanometres range. The device proposed here (Figure:3) depends on inertial focusing phenomena where disparate drag and lift forces act on the hemocytes and position the hemocytes in the microfluidic channels. The inertial focusing of the particles in the channels is grouped mainly into two categories[35],[36]: (i) primary lift forces $\left[F_{L}\right]$ - wall interaction, shear gradient lift, and drag forces; (ii) secondary forces $\left[F_{D}\right]$ - Dean's flow formation. The positioning of the particles is determined by the primary and secondary forces which are continuously varying along the cross-section of the channels. The lateral migration of the particles because of the lift forces are balanced by the drag forces for the final positioning of the particles. Additional secondary forces act on the particles when the channels are not straight. These secondary forces cause secondary flow in a lateral direction along the cross-section of the channels which is called Dean Flow in the serpentine channels. For a given geometry, the forces can be manipulated by varying flow rates and thus controlling the position of the particles in the liquid flow. If $F_{D}>>F_{L}$, inertial focusing is not effective while mixing takes place, and if $F_{D}<<F_{L}$ inertial forces dominate, resulting in the focusing of the particles. For micro-scale blood plasma separation 
depending upon the dilution and varying flow rates, the cells should be manipulated to get focused in a required position.

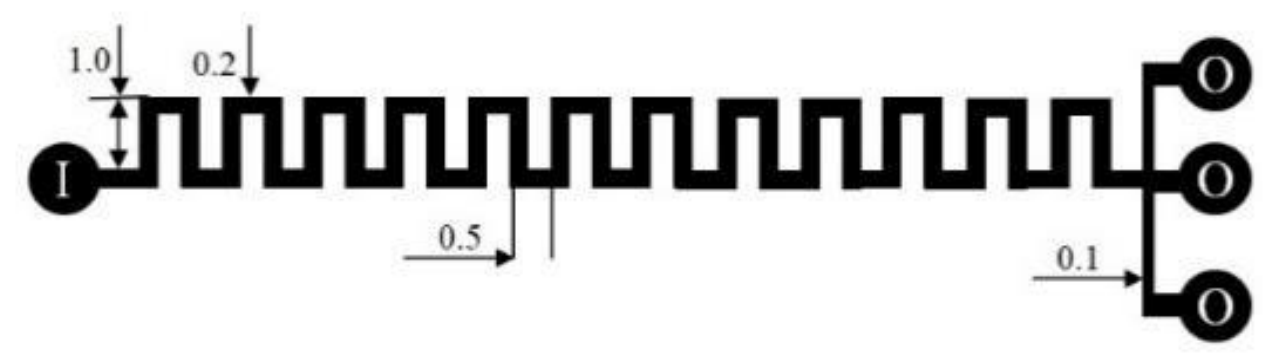

Figure 3: Design of microfluidic device with serpentine channels and fabrication to approximately $50 \mu \mathrm{m}$ depth. All dimensions are in $\mathrm{mm}$. (I- Inlet, O- Outlets)

\section{Materials and Methods}

\subsection{Fabrication methods:}

In this present work hot embossing, photolithography, 3D Printing, and mechanical micro-milling have been used to obtain the surfaces for calculating surface energy. PMMA, PC wafer substrates, and Glass-slides were measured were obtained from the Melbourne Centre for Nanofabrication $(\mathrm{MCN})$, Australia. Microfluidic devices fabricated using mechanical micromachining were further studied for blood plasma separation.

\subsubsection{D Printing:}

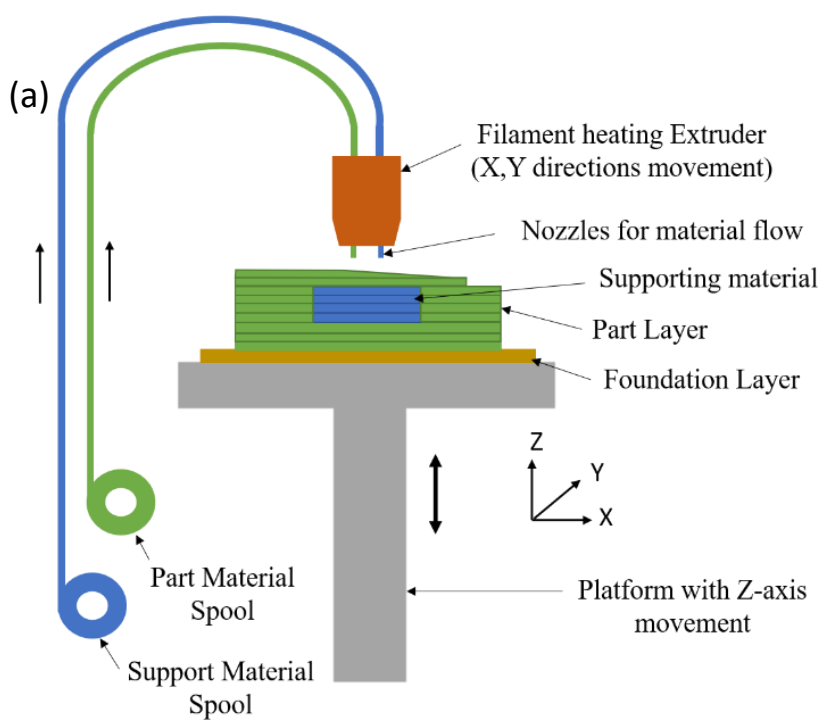

(b)

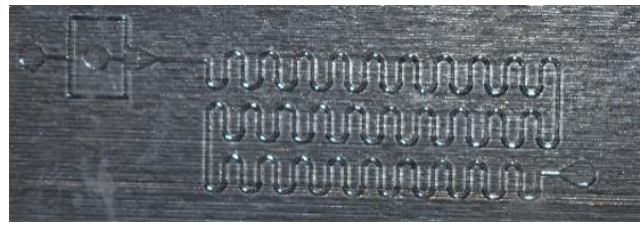

(c)

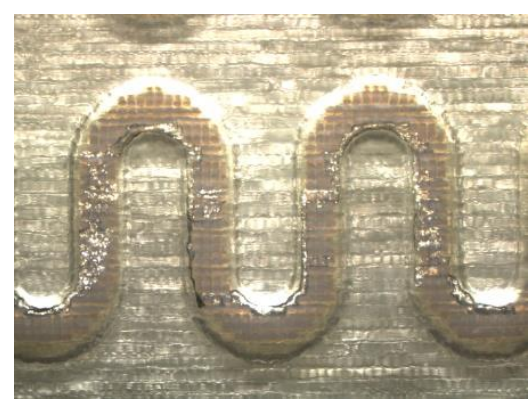

Figure 4: Microfluidic channels fabricated using the 3D printing technique

(a) Schematic of Fused deposition modeling (b) 3D printed microfluidic device (c) Close-up view of serpentine channels in the microfluidic device 
3D Printed microfluidic channels were successfully fabricated with Stratasys F270 and PMMA (Vero Clear) material using the Fused deposition modeling (FDM) technique. This technique involves extruding thermal plastic material into layers using a heated nozzle onto a platform that moves in the Z-direction which is controlled using precision motors. The coordinates for the movement and the layer heights were generated using Grabcad print slicing software. Serpentine channels with $1 \mathrm{~mm}$ and $0.5 \mathrm{~mm}$ channel width and a layer height of $0.127 \mathrm{~mm}$ were fabricated using the FDM technique. Closed channels as shown in figure 4 was printed using dissolvable support material provided by Stratasys ltd, while open channels were fabricated without any support material. The design of the device that was printed consisted of the smallest feature dimension in the channel provided was $0.1 \mathrm{~mm}$. The variations in the dimensions achieved after fabrication showed a deviation of $\pm 0.2 \mathrm{~mm}$. This shows the $3 \mathrm{D}$ printed devices used in this experiment are however more suitable for milli-fluidic applications.

\subsubsection{Hot Embossing:}

A combination of photolithography and electroplating as shown in figure 5 is used to make Ni-master for hot embossing. Initially, a Silicon wafer is coated with SU-8 2005 and SU-8 2025 respectively at different speeds, later exposed to UV light and baked up to $95^{\circ} \mathrm{C}$. The coated wafer is then treated with the SU-8 developer solution. For Ni-electroplating the developed wafer is sputtered with $\mathrm{Cr}$ and $\mathrm{Ni}$ sputtering and later plunged to galvanic bath for 6 hours. Later electroplated $\mathrm{Ni}$-master is heated up to $400^{\circ} \mathrm{C}$ to remove any residues of SU-8. This Ni-master is used to fabricate hot-embossed microfluidic devices using the hot embosser machine EVG 520 IS at $135^{\circ} \mathrm{C}$ and $25 \mathrm{KN}$ force. The detailed procedure for fabricating hot-embossed microfluidic devices is given elsewhere[37]. 


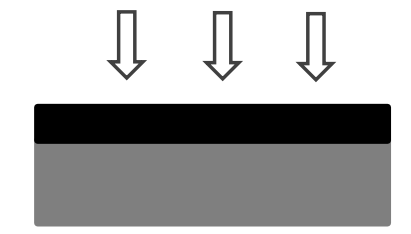

a) SU-8-2005 coated and exposed to UV light

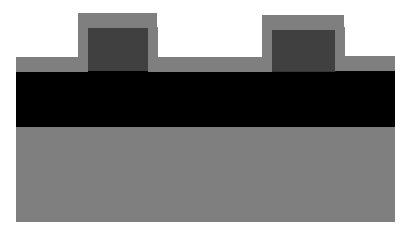

d) Ni- Electroplating

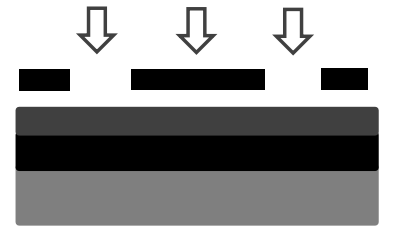

b) SU-8-2025 Coated and exposed to UV

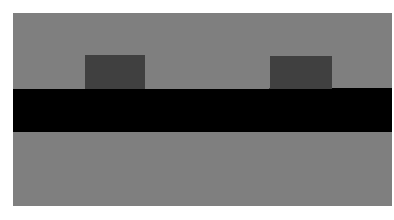

e) Hot-embossing of Ni-master on PMMA

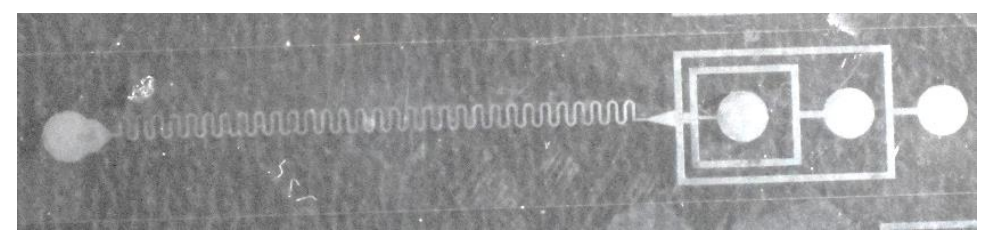

g) Hot embossed microfluidic channels on PMMA wafer

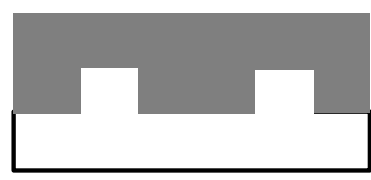

c) Cr-Ni Seed layer Sputtering

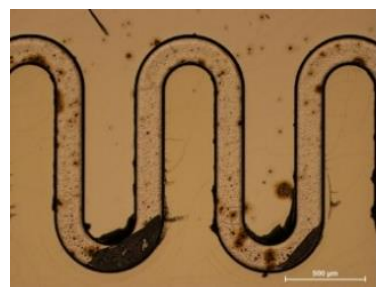

f)Microscopic view of the profiles on Ni-Master

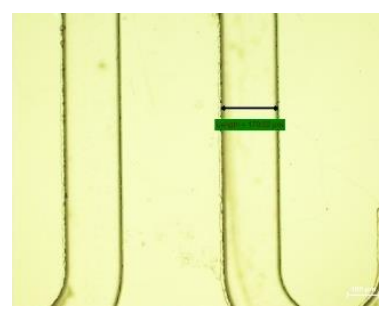

h) Microscopic view of Hot embossed microfluidic device

Figure 5: Schematic for development of Hot embossed microfluidic devices

\subsubsection{Photo-lithography:}

Silicon wafer coated with AZ40XT (positive resist) was baked, exposed to UV light with the mask placed on the wafer, and is developed in AZ726MiF solution. The wafer is exposed to dry etching gases and coated with Teflon. The PDMS base and the curing agent (Sylgard 184 from Dow Corning) are mixed at a 10:1 ratio using a centrifugal mixer at 1000 RPM. The mixture is then poured into a petri dish along with the Teflon coated wafer and placed in a vacuum chamber for 20 minutes to remove any bubbles formed. It is later cured in a hot oven at $65^{\circ} \mathrm{C}$ for 2 hours and cooled to room temperature. PDMS devices are later peeled off from the wafer and were used for surface energy measurement. The schematic process for developing the PDMS microfluidic devices is shown in figure 6. 


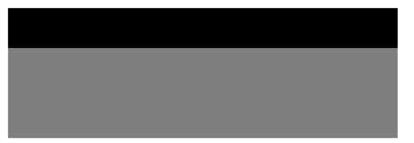

a) AZ40XT coated on Si- wafer

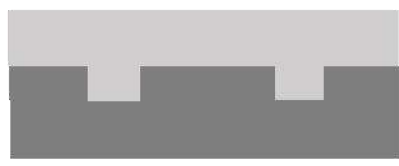

d) Etched Wafer coated with PDMS

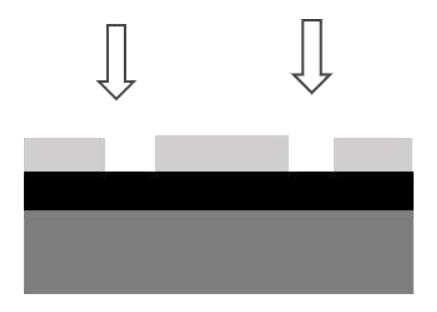

b) Coated Si- wafer exposed to UVlight with mask placed on it

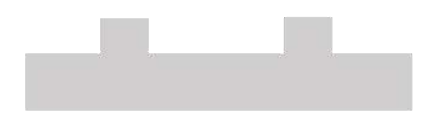

e) PDMS channels peeled from the SiWafer

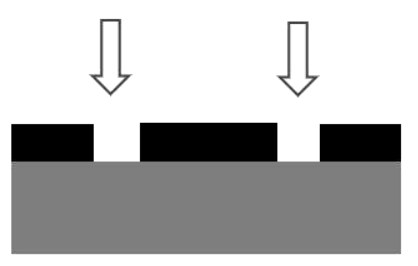

c) UV exposed Si- Wafer exposed to dry etching

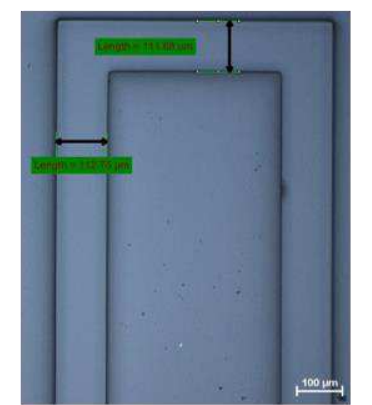

f) Microscopic view of PDMS channels

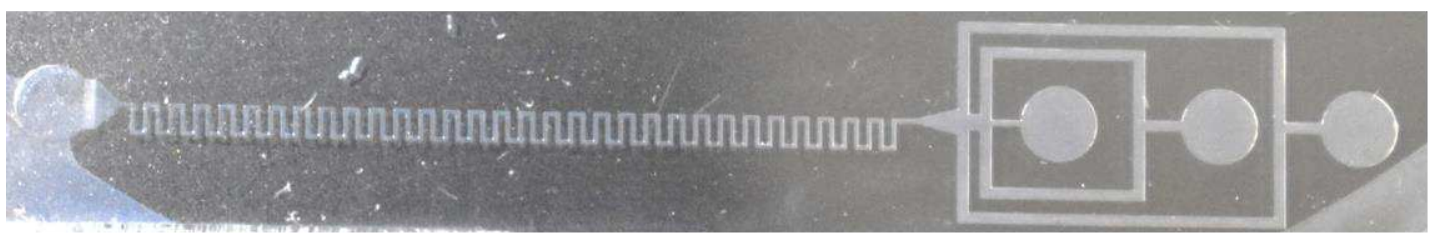

g) Microfluidic channels on PDMS block

Figure 6: Schematic for development of PDMS microfluidic devices fabricated using soft-lithography

\subsubsection{Device fabrication using CNC Micro-milling}

The Micromachining tool (MMT)[11] setup used for machining as shown in figure 7 has three major systems - mechanical structure, positioning system with its motion driver, controller for the stages, and spindle with its drive system. The high-frequency spindle can reach a maximum speed up to 100,000 rpm with a $0.1 \mu \mathrm{m}$ run-out resolution. The accuracy positioning system, Newport controller (Model ESP 300), with $0.1 \mu \mathrm{m}$ resolution was used to control relative motion between the tool and the workpiece. According to the studies performed on the MMT, the amplitude of vibration at different speeds varied from $0.2 \mu \mathrm{m}$ to $1.4 \mu \mathrm{m}$ which shows good rigidity and stability. The limit switches used are optical for the linear stages and have a travel range of $150 \mathrm{~mm}$. The whole setup is mounted on an anti-vibration 
table with a cast iron base of $20 \mathrm{~mm}$ thick to absorb the vibrations. A $200 \mu \mathrm{m}$ two flute end mill used for this experiment was sourced from Reinforced Tooling Solutions, India. Surface roughness and surface energy were measured on the surface of the slots to determine the most suitable polymer for fabricating microfluidic devices with serpentine profiles. Initially, a depth of $100 \mu \mathrm{m}$ was machined, and later for characterization, slots were machined with the required parameters as mentioned above. Similarly, for the microfluidic device, the initial depth of cut was $45 \mu \mathrm{m}$ followed by $5 \mu \mathrm{m}$ to achieve $50 \mu \mathrm{m}$ channel depth. A stepover of $20 \%$ is used while machining. Before the surface roughness was inspected, the milled slots were exposed to compressed air to remove contaminants attached to the surface.
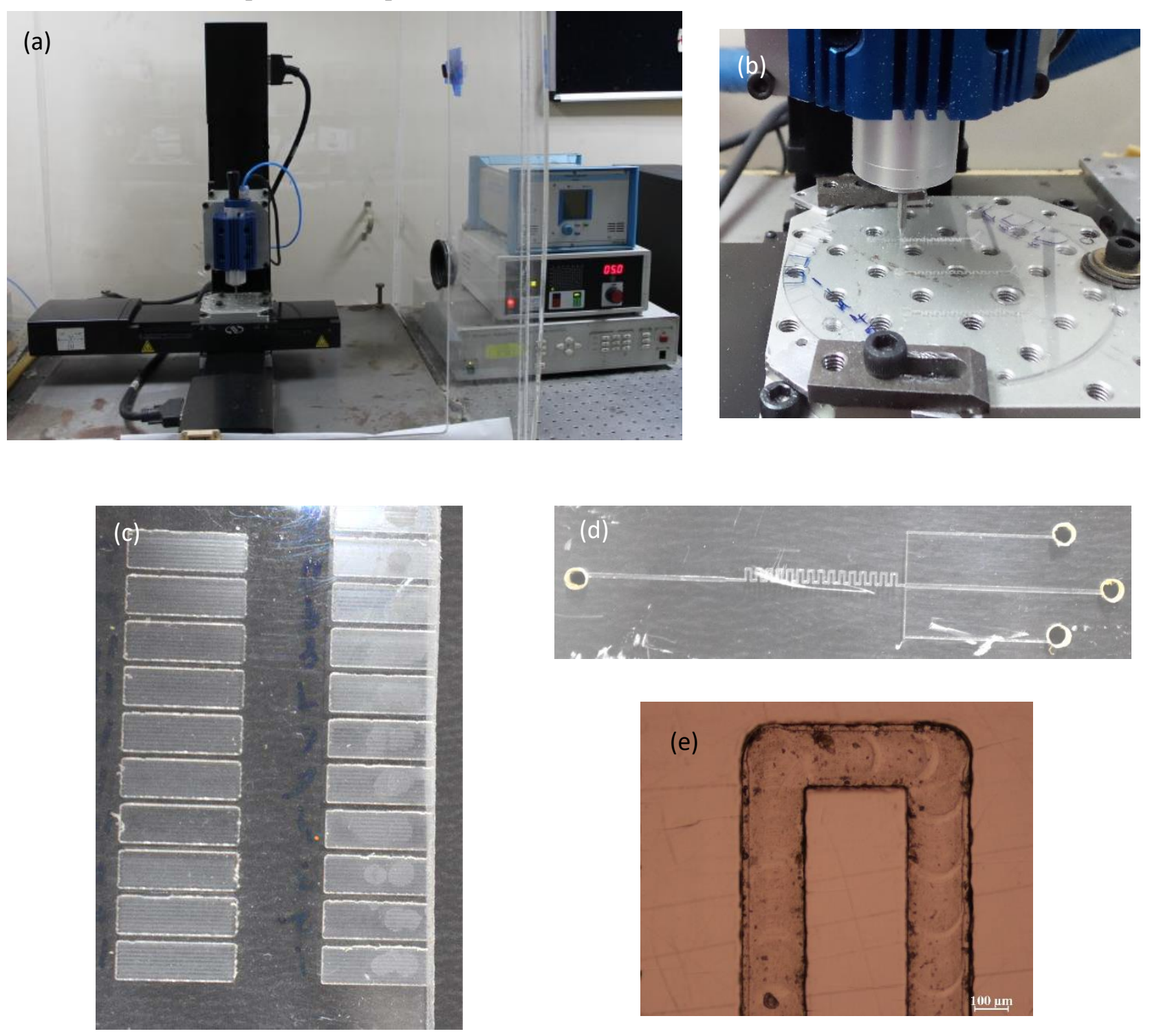

Figure 7: a) Micromachining tool (MMT) which was used to fabricate the polymeric microfluidic devices b) closeup view in the left while machining c) Slots machined to measured surface roughness on PMMA d) Microfluidic device fabricated using mechanical micromilling e)Microscopic view of the microfluidic channel 


\subsection{Surface characterization}

The roughness measurement on the milled slots was performed with a Stylus profilometer while Veeco non-contact 3D surface profilometer was used to view the surface of the milled microfluidic channel. For viewing inside the channel using the non-contact profilometer, the surface of the channel was sputtered with gold for 10 minutes. A stereo microscope (Stemi CS2000) was used to verify burrs present on the side of the wall and the experiments were repeated three times to validate repeatability. After evaluating the surface roughness (Ra), surface energy, and burr formation, microfluidic devices with serpentine and EC profiles were machined using suitable parameters.

Fowke's method with Young's equation (equation:1) and Dupre's equation (equation:2) as described below was used to calculate the surface energy by measuring the contact angle from two liquids[38]. Contact angle measurements were carried using a goniometer with water $\left(\boldsymbol{\sigma}_{\boldsymbol{L}}^{\boldsymbol{P}}=46.4 \mathrm{mN} / \mathrm{m}\right.$, $\sigma_{L}^{D}=26.4 \mathrm{mN} / \mathrm{m}$ were considered from Kruss technical note, TN306e $)$ and diiodomethane $\left(\sigma_{L}=\sigma_{L}^{P}=\right.$ $50.8 \mathrm{mN} / \mathrm{m}$ ) as polar and dispersive components, respectively.

Young's Equation: $\sigma_{S}=\sigma_{S L}+\sigma_{L} \cdot \cos \theta$

Dupre's Equation: $I_{S L}=\sigma_{S}+\sigma_{L}-\sigma_{S L}$

$I_{S L}=2\left[\sqrt{\left(\sigma_{L}^{D} \sigma_{S}^{D}\right)}+\sqrt{\left(\sigma_{L}^{P} \sigma_{S}^{P}\right)}\right]$

$\sigma_{S} \quad=$ Overall surface energy of the solid $(\mathrm{mN} / \mathrm{m})$

$\sigma_{L} \quad=$ Overall surface energy of the liquid

$\sigma_{S L} \quad=$ Interfacial tension of solid and liquid

$I_{S L} \quad=$ Energy of Adhesion per unit area

$\sigma_{L}^{D} \quad=$ Dispersive component of the surface tension of wetting liquid

$\sigma_{S}^{D} \quad=$ Dispersive component of the surface tension of solid

$\sigma_{L}^{P} \quad=$ Polar component of the surface tension of wetting liquid

$\sigma_{S}^{P} \quad=$ Polar component of the surface tension of Solid

$\boldsymbol{\theta}=$ Contact angle between the solid and liquid. 


\subsection{Flow Cytometry}

Open channels formed after micro-milling were laminated with acrylic tape while inlet and outlet holes were drilled with a $2 \mathrm{~mm}$ drill and connected to the piping using Araldite. Blood samples collected from the volunteers were diluted to 1:40,1:60, 1:80, and 1:100 dilution rates (1unit of blood in 40 units of $0.9 \% \mathrm{NaCl}$ for $1: 40$ dilution). The diluted blood samples were pumped with a flow rate of $0.3 \mathrm{ml} / \mathrm{min}$ using a New-Era 300 microfluidic syringe pump. The whole device was mounted under a Nikon Eclipse 80i microscope for viewing the flow as shown in figure 8. Blood flow in the experiments was viewed under a microscope at 1:40 dilution as a further increase in dilution rate will need fluorescent cells for viewing. Flow cytometry data were collected at different dilution rates assuming higher efficiency of inertial focusing at higher dilutions. The same device was used for all the experiments and the channels were washed with 5\% hypochlorite, Phosphate Buffered Saline (PBS), and $0.9 \% \mathrm{NaCl}$ consecutively after every experiment. The blood samples were collected in vacutainers and the blood cells were counted using BD FACS Canto ii Flow Cytometer within 4 hours of each flow experiment. The cell count in the outlets was calculated as the percentage of cells from the outlets as shown below.

$$
\text { Cell count } \%=\frac{\text { No. of cells from the required outlet } \times 100}{\text { Total number of cells from all the outlets }}
$$
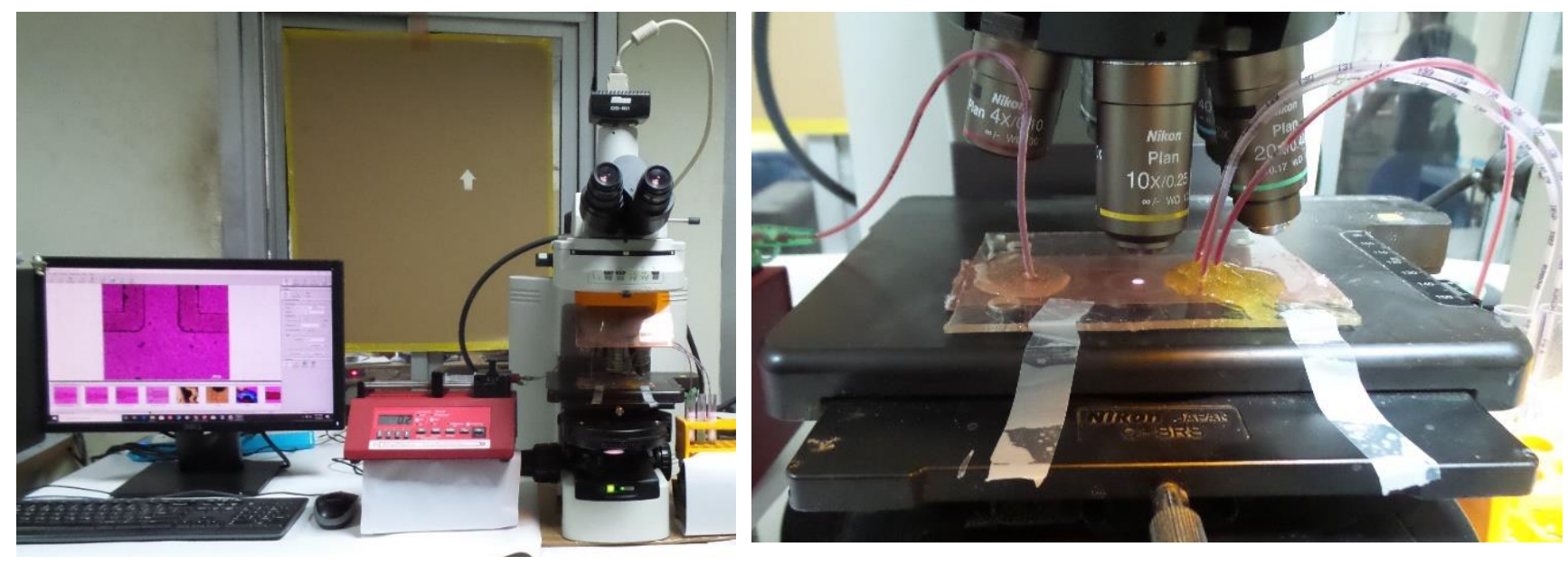

Figure 8: A photograph of experimental setup taken during blood flow experiments and the microfluidic device mounted under the microscope and attached to the syringe pump 


\section{Results and Discussion}

\subsection{Surface Energy on surfaces fabricated using different techniques:}

Contact angles measurements obtained as shown in figure 9 were used to calculate the surface energy shown in Table 1 of the materials commonly used in fabricating microfluidic devices. From the contact angle measurements, the machined PMMA surface shows less wettability compared to the machined PC surface. Also, PDMS is most hydrophobic compared to all the surfaces used in this study. Comparable surface energy with PDMS or Glass is desirable as these materials are extensively used in fabricating microfluidic devices. Surface energy is measured on the micro-milled slots of PMMA and PC, Glass, PDMS, and Hot embossed PMMA surfaces (Figure 8). However, the machined PMMA surface exhibited less surface energy compared to that of machined PC showing lower wettability and adhesion.

\begin{tabular}{|c|c|c|c|c|c|}
\hline \multicolumn{6}{|c|}{$\begin{array}{c}\text { Table 1: Contact angles of Water, Diiodomethane, and Surface energy of surfaces fabricated using } \\
\text { different methods }\end{array}$} \\
\hline S.No & Fabrication method & Material & Water $\left(^{0}\right)$ & Diiodomethane $\left(^{0}\right)$ & $\begin{array}{c}\text { Surface energy } \\
(\mathrm{mN} / \mathrm{m})\end{array}$ \\
\hline \multirow{2}{*}{1} & \multirow{2}{*}{$\begin{array}{l}\text { Mechanical } \\
\text { micro-machining }\end{array}$} & $\mathrm{PC}$ & 73.45 & 37.10 & 44.37 \\
\hline & & PMMA & 85.58 & 42.28 & 39.52 \\
\hline 2 & Hot Embossing & PMMA & 73.64 & 36.40 & 46.55 \\
\hline 3 & Soft lithography & PDMS & 104.35 & 61.80 & 27.54 \\
\hline 4 & 3D Printing & VeroClear & 49.89 & 60.25 & 46.45 \\
\hline \multirow{3}{*}{5} & \multirow{3}{*}{$\begin{array}{l}\text { Commercially } \\
\text { obtained materials }\end{array}$} & $\mathrm{PC}$ & 71.44 & 26.04 & 49.22 \\
\hline & & PMMA & 73.86 & 43.37 & 42.25 \\
\hline & & Glass slide & 93.07 & 68.90 & 25.30 \\
\hline
\end{tabular}

According to Wenzel's law, roughness induces more wettability to the machined surfaces as the liquids can penetrate the peaks and valleys of the rough surface. Similarly, according to Cassie-Baxter law wettability is reduced if the liquid is not able to penetrate the peak and valleys due to air gaps of machined surfaces. The surface energy of the machined surfaces is slightly lower than that of the commercially obtained material surface (Figure 10). This was observed on the machined surfaces in some instances where peaks and valleys were present consistently. Therefore, roughness aided in more wettability (hydrophilic) of machined surfaces compared to glass and PDMS surfaces and less wettability compared to embossed and molded surfaces. Among all the fabrication techniques of polymeric microfluidic channels, micro-machined surfaces exhibited the least surface energy, though not comparable with glass and PDMS surfaces. From the surface-energy point of view, this research 
shows PMMA is a preferable choice for material compared to PC for fabricating microfluidic devices when using mechanical micro-milling.

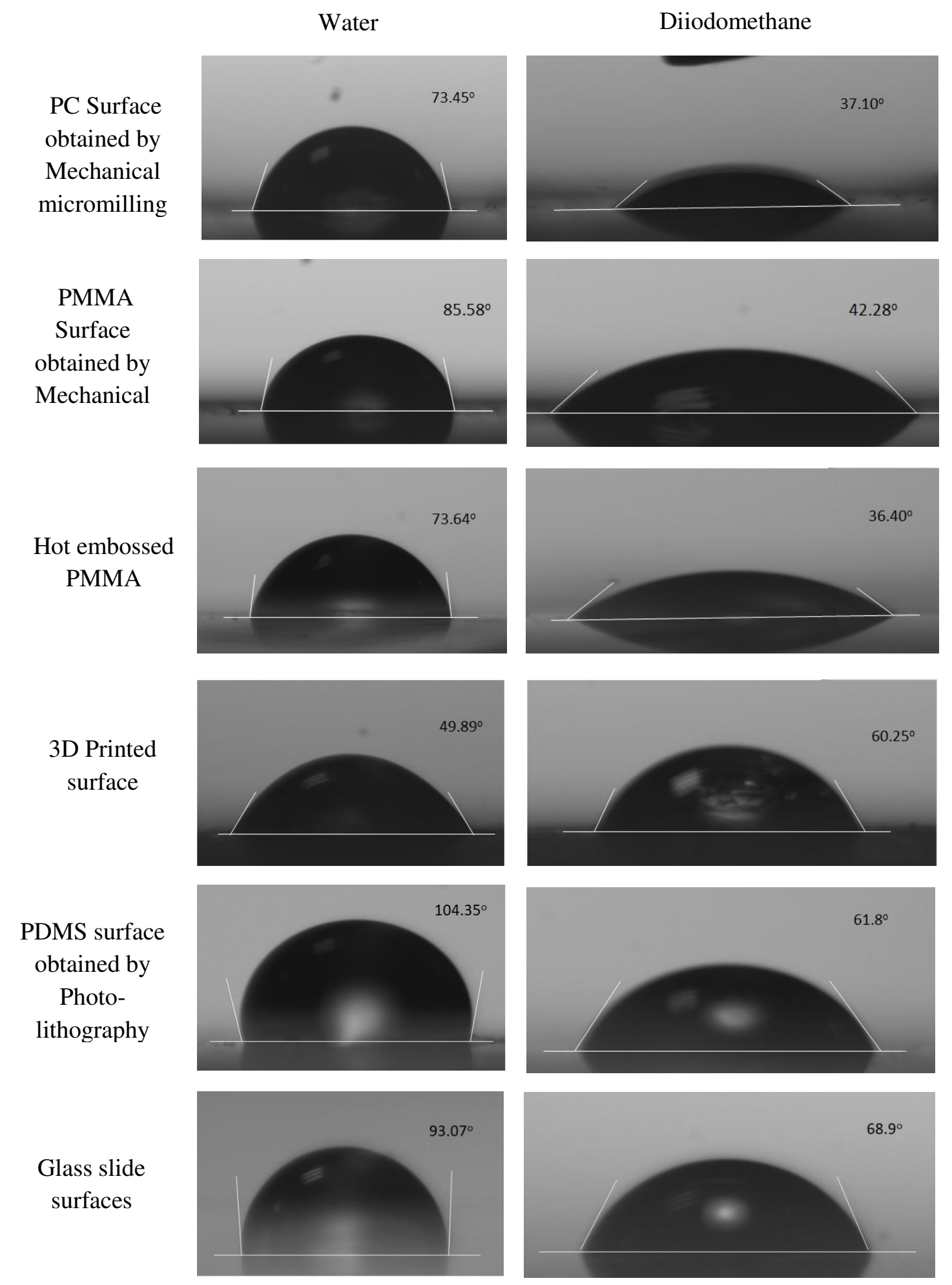

Figure. 9: Water and Diiodomethane contact angles on polymeric surfaces fabricated using various methods and measured using Goniometer for calculating surface energy (showed in the decreasing order of surface energy from top to bottom). 


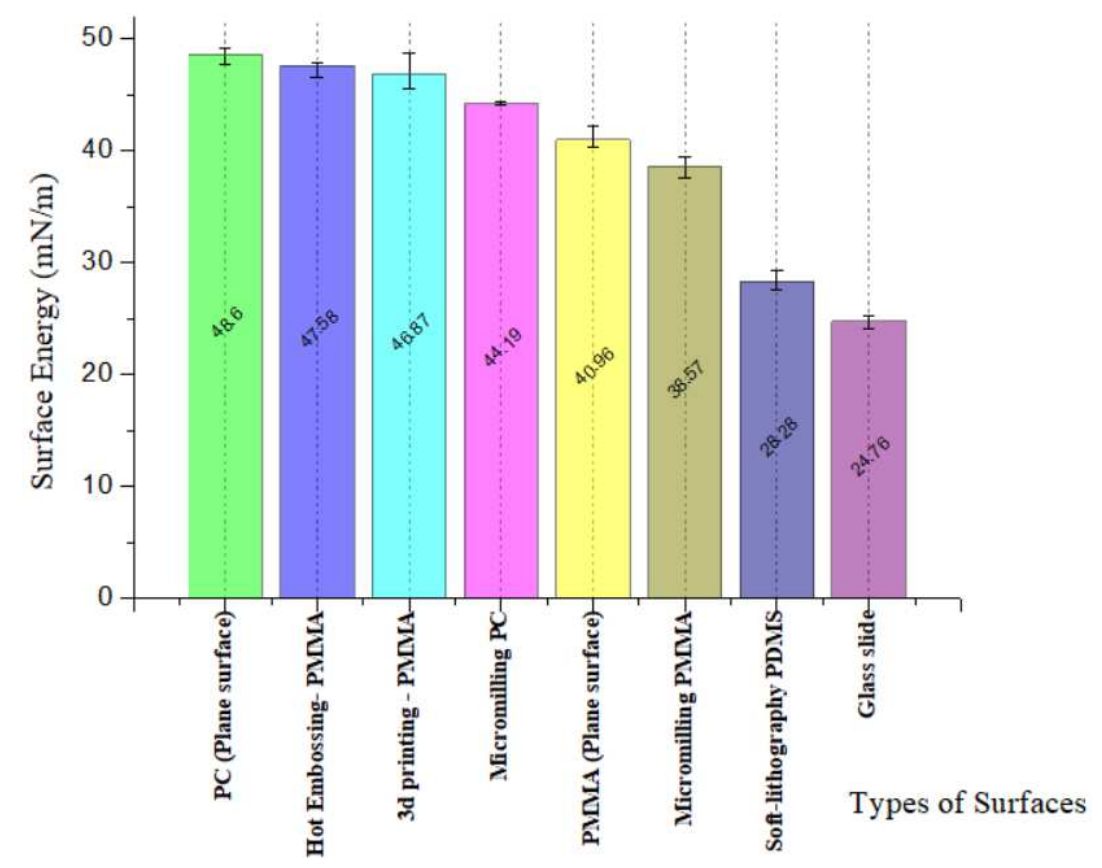

Figure 10: Surface Energies of different surfaces fabricated with various methods calculated using Fowke's theory and contact angles (Average values are shown in the graph)

\subsection{Surface Roughness measurements}

A total of 21 slots with dimensions $8 \mathrm{~mm} \times 5 \mathrm{~mm}$ were machined on a $2 \mathrm{~mm}$ thick PMMA and PC wafer using an in-house built mechanical micro-machining tool as shown in figure $7 \mathrm{c}$. The full factorial design of experiments was chosen with feed rate $(0.5,1.0$, and $1.5 \mathrm{~mm} / \mathrm{sec})$ and depth-of-cut $(5,10,15$, $20,25$, and $50 \mu \mathrm{m})$ as varying parameters. The experimental results of milling showed that the least surface roughness obtained is $0.2 \mu \mathrm{m}$ on PMMA and PC material with the cutting conditions at $0.5 \mathrm{~mm} / \mathrm{s}$ feed rate, $5 \mu \mathrm{m}$ depth of cut, and 20,000 rpm. Lower Ra values were observed at the lower depth-of-thecut at all feed rates (Table 2 and Table 3 for PMMA and PC, respectively), showing depth-of-cut is the most significant variable influencing Ra. From the experiments, it is confirmed that at a lower depth of cut and feed rates, the peaks and valleys of the surface were consistent as shown in Figure 11. PMMA and $\mathrm{PC}$ have different $\mathrm{T}_{\mathrm{g}}$ 's and are approximately $105^{\circ} \mathrm{C}$ and $150^{\circ} \mathrm{C}$, respectively. Assuming the temperature during machining reaches more than $T_{\mathrm{g}}$ and the material is in a rubbery zone due to viscoelasticity and machining time did not vary for a given machining parameter. As the temperature increases, the viscosity of the polymer in the rubbery zone decreases easing material flow during 
machining. The response of the polymer during machining depends on the rate of disturbance propagation in polymer chains and their relaxation time. As the material removal rate increases, the time for propagation of disturbance and relaxation rates affects the surface quality. The disturbance in PMMA polymer chains is early compared to PC due to its less Tg and resulting in a higher volume of material flow. This flow of material in the rubbery zone facilitates the variation of Ra values between PMMA and PC. Also, the lowest depth of cut used in these experiments is $5 \mu \mathrm{m}$ which is close to the size of the edge radius in micro-tools. It may have caused ploughing, leading to variation in Ra values.

(a)

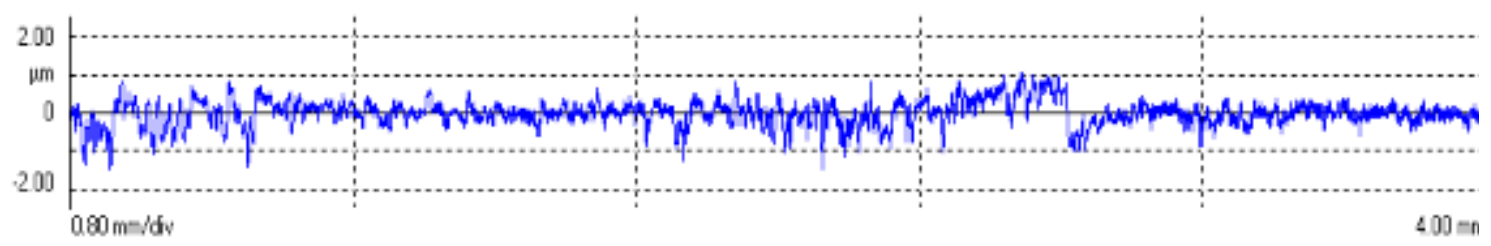

(b)

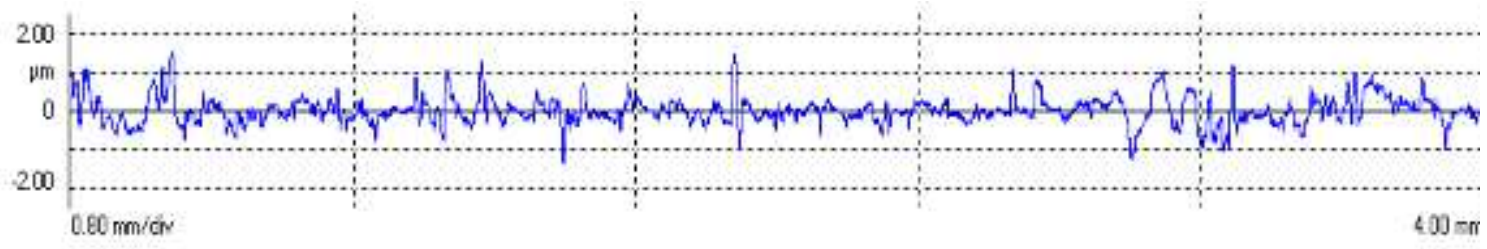

Figure 11: Sample surface roughness profiles on machined (a) PMMA and (b) PC slots measured using stylus profilometer at a feed rate of $0.5 \mathrm{~mm} / \mathrm{s}$ and depth of cut of $5 \mu \mathrm{m}$

Unlike metals, Ra values did not follow any trend which makes surface finish unpredictable (Figure 12). Adhering to the polymeric material further blunted the milling tool depriving the quality of the machined surface. This adhesion increases the edge radius of the tool, making ploughing more effective during which the material is pushed away from the tool path instead of complete removal. If the tool stays in the same position during machining, rubbing takes place between the tool and the workpiece which is in the viscoelastic state. As the rubbing continues the viscoelastic polymer chains may climb the tool (Weissienberg effect) due to its rotation. As the climbed polymer adheres to the tool shearing action may start again, leading to material removal. This cycle of climbing and material removal leaves disparate peaks (Figure 13 and Figure 14) on the machined surface which makes the surface more complex to predict the surface finish. Though glass transition temperature is attributed to the difference in surface roughness during machining of PMMA and PC, better surface roughness only 
cannot be a parameter to choose material for fabricating microfluidic devices. Apart from roughness, the adhesion and climbing effects while machining polymers affect the wettability of the surface and change the surface energy of machined surfaces.

\begin{tabular}{|c|c|c|c|c|c|c|c|c|c|}
\hline $\begin{array}{l}\text { Feed-rate } \\
(\mathrm{mm} / \mathrm{sec})\end{array}$ & \multicolumn{3}{|c|}{0.5} & \multicolumn{3}{|c|}{1} & \multicolumn{3}{|c|}{1.5} \\
\hline $\begin{array}{l}\text { Depth of cut } \\
(\mu \mathrm{m})\end{array}$ & Trail-1 & Trail-2 & Trail-3 & Trail-1 & Trail-2 & Trail-3 & Trail-1 & Trail-2 & Trail-3 \\
\hline 5 & 0.2468 & 0.2508 & 0.277 & 0.4382 & 0.4843 & 0.4863 & 0.155 & 0.1676 & 0.1824 \\
\hline 10 & 0.1373 & 0.1586 & 0.2742 & 0.3187 & 0.3423 & 0.4973 & 0.1794 & 0.2472 & 0.2697 \\
\hline 15 & 0.3115 & 0.3464 & 0.35 & 0.368 & 0.4095 & 0.4485 & 0.1952 & 0.2091 & 0.2688 \\
\hline 20 & 0.1952 & 0.2091 & 0.2688 & 0.2161 & 0.2749 & 0.3412 & 0.15 & 0.2556 & 0.2564 \\
\hline 25 & 0.148 & 0.1954 & 0.2304 & 0.148 & 0.1565 & 0.195 & 0.2163 & 0.32 & 0.3215 \\
\hline 50 & 0.3659 & 0.4016 & 0.4411 & 0.6487 & 0.71 & 0.9704 & 0.6472 & 0.841 & 1.0725 \\
\hline \multicolumn{10}{|c|}{$\begin{array}{l}\text { Table 3: Surface roughness Ra values on the PC slots machined using MMT measured with a Stylus } \\
\text { profilometer }\end{array}$} \\
\hline $\begin{array}{l}\text { Feed-rate } \\
(\mathbf{m m} / \mathbf{s e c})\end{array}$ & \multicolumn{3}{|c|}{0.5} & \multicolumn{3}{|c|}{1} & \multicolumn{3}{|c|}{1.5} \\
\hline $\begin{array}{l}\text { Depth of cut } \\
(\mu \mathrm{m})\end{array}$ & Trail-1 & Trail-2 & Trail-3 & Trail-1 & Trail-2 & Trail-3 & Trail-1 & Trail-2 & Trail-3 \\
\hline 5 & 0.2278 & 0.2521 & 0.264 & 0.3223 & 0.3265 & 0.402 & 0.3357 & 0.3508 & 0.3649 \\
\hline 10 & 0.282 & 0.3363 & 0.3578 & 0.3502 & 0.413 & 0.5163 & 0.4762 & 0.4766 & 0.4913 \\
\hline 15 & 0.3396 & 0.3531 & 0.4419 & 0.5422 & 0.5944 & 0.6845 & 0.5384 & 0.5904 & 0.6981 \\
\hline 20 & 0.3263 & 0.4576 & 0.5206 & 0.2309 & 0.3849 & 0.4864 & 0.6497 & 0.6582 & 0.7827 \\
\hline 25 & 0.3213 & 0.395 & 1.0356 & 0.3037 & 0.4921 & 0.7286 & 0.5562 & 0.721 & 0.7817 \\
\hline 50 & 0.4046 & 0.4576 & 1.6477 & 0.4329 & 0.6186 & 0.6267 & 0.3198 & 0.48 & 0.9825 \\
\hline
\end{tabular}
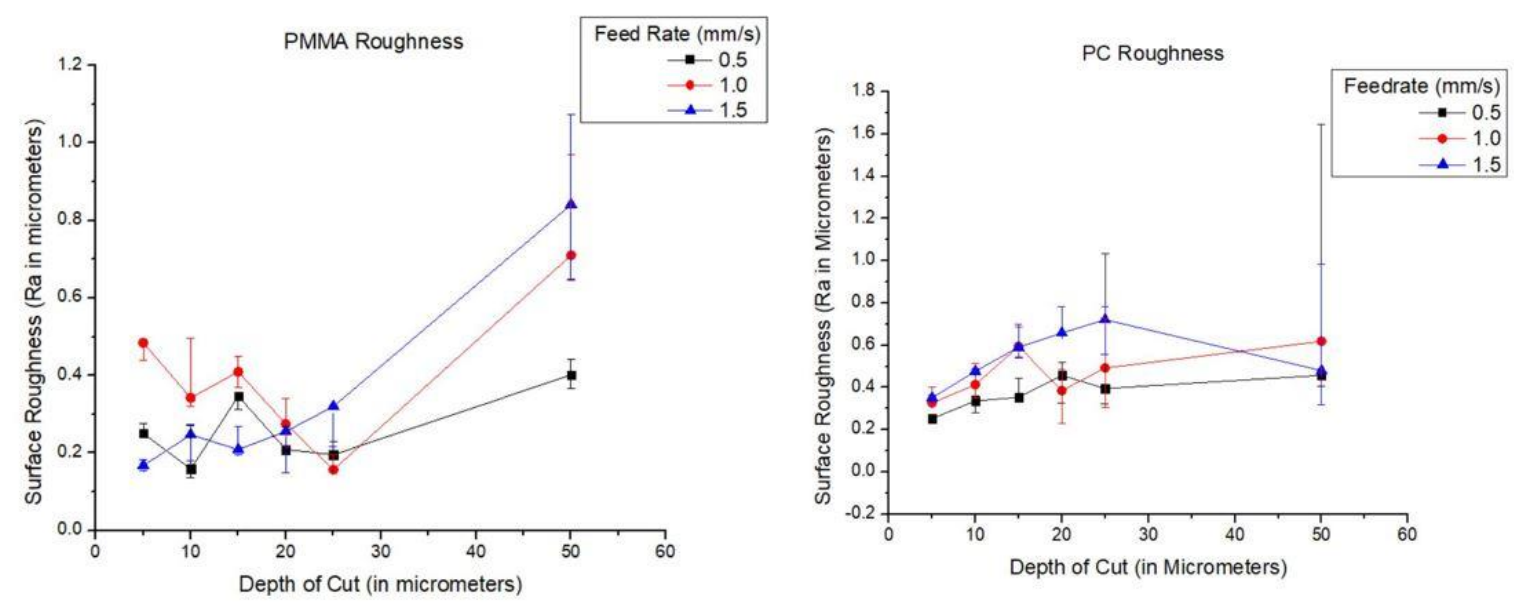

Figure 12: The unpredictable trend of Ra values from PMMA and PC slots at varying parameters due to Viscoelasticity and Weissienberg effect 
(a)

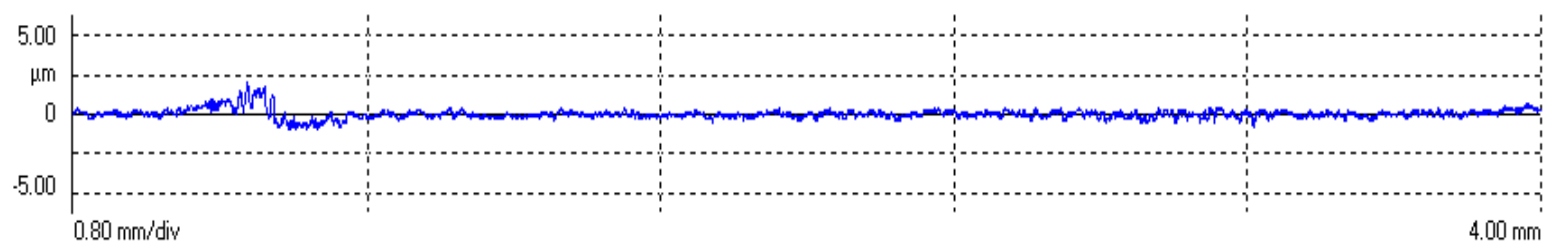

(b)

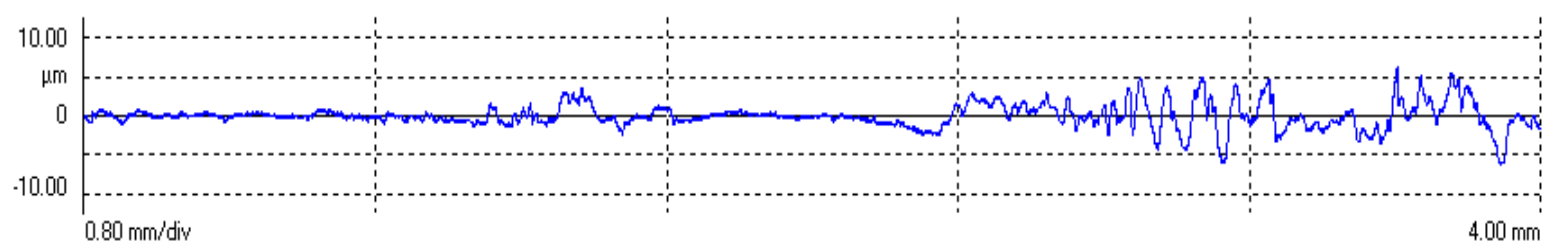

Figure 13: Sudden peaks and valleys (Weissenberg effect) observed on surface roughness profiles (a) PMMA (b) PC

Suface Stats:

Ra: $845.85 \mathrm{~nm}$

Rq: $1.24 \mathrm{um}$

Rt: 52.83 um

Measurement Info

Magnification: 20.75

Measurement Mode: VSI

Sampling: $404.82 \mathrm{~nm}$

Array Size: 736 X 480

Sufface Stats:

Ra: $9.83 \mathrm{~nm}$

$\mathrm{Rq}: 12.16 \mathrm{~nm}$

Rt: $99.76 \mathrm{~nm}$

Measurement Info:

Magnification: 24.76

Measurement Mode: Intensity

Sampling: $339.29 \mathrm{~nm}$

Array Size: 736 X 480
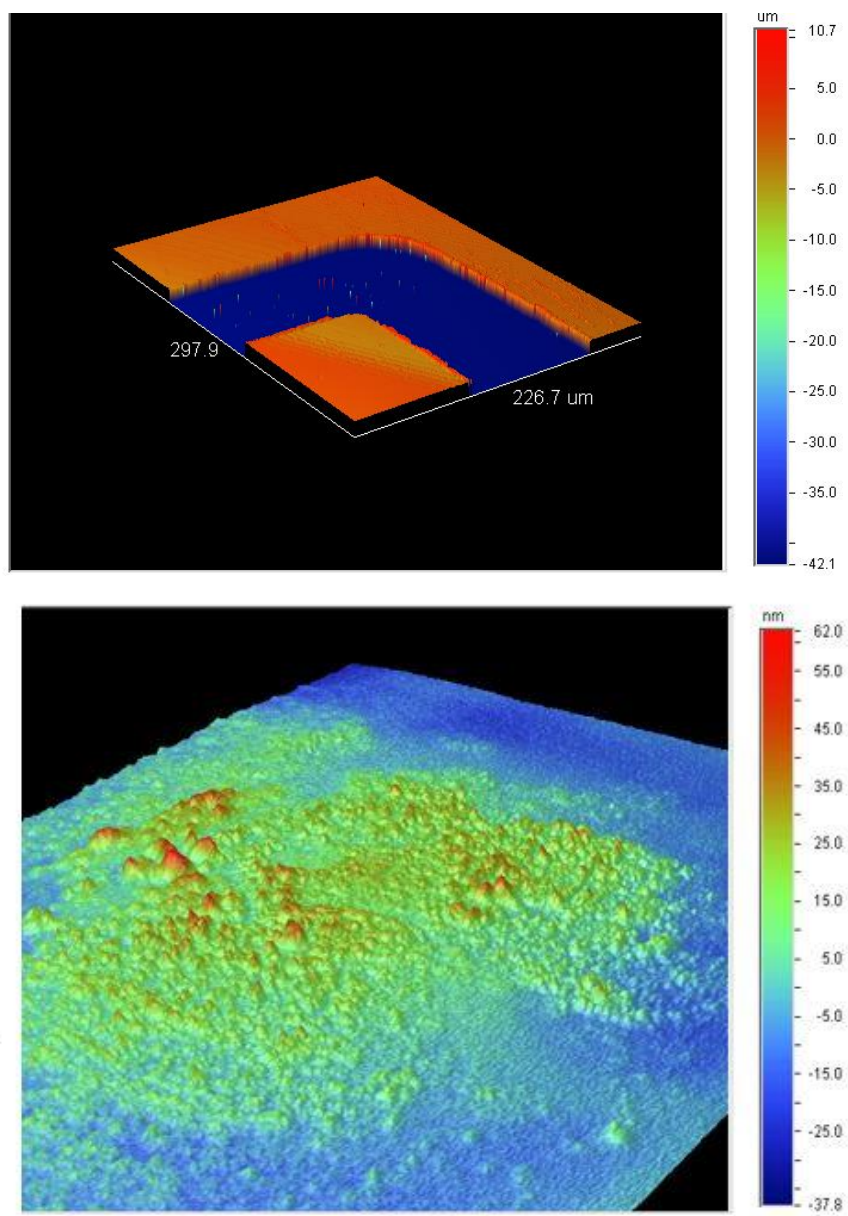
Figure 14: Machined microchannels and Weissenberg effect observed on the surface of the PMMA microfluidic channel observed through 3D surface profilometer (Peaks- Red)

\subsection{Formation of Burrs}

Burr formation is more pronounced in PC when compared to PMMA (Figure 15), making PMMA preferable for machining microfluidic devices. Burrs are detrimental to the quality of the microfluidic device as it affects the fluid flow. These burrs on PMMA and PC channel walls are inhibited by the side flow of the polymer chains while machining in a rubbery zone. This flow is due to the extrusion of the polymer chains along the flank face of the tool caused by the interaction stress between tool and material. PC having higher molecular weight compared to PMMA needs larger force to fracture these extruded chains resulting in more burrs. Slight burr formation in the PMMA channel can be observed near the edges of the 3D serpentine profile as shown in Figure 16. Burr formation is inevitable due to the presence of cutting-edge radius and its effects in micromachining.
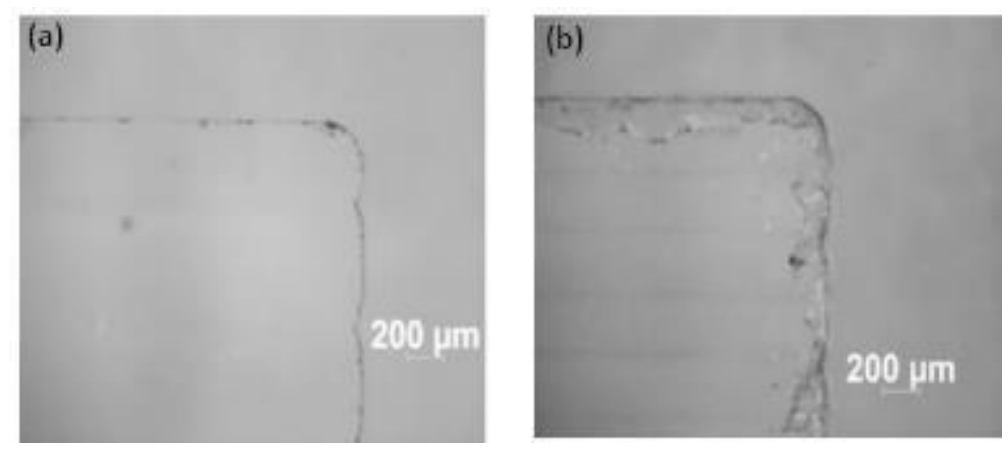

Figure 15: Microscopic view at the edges showing burr formation after machining; (a) PMMA, (b) PC (viewed using Stemi CS2000 microscope)

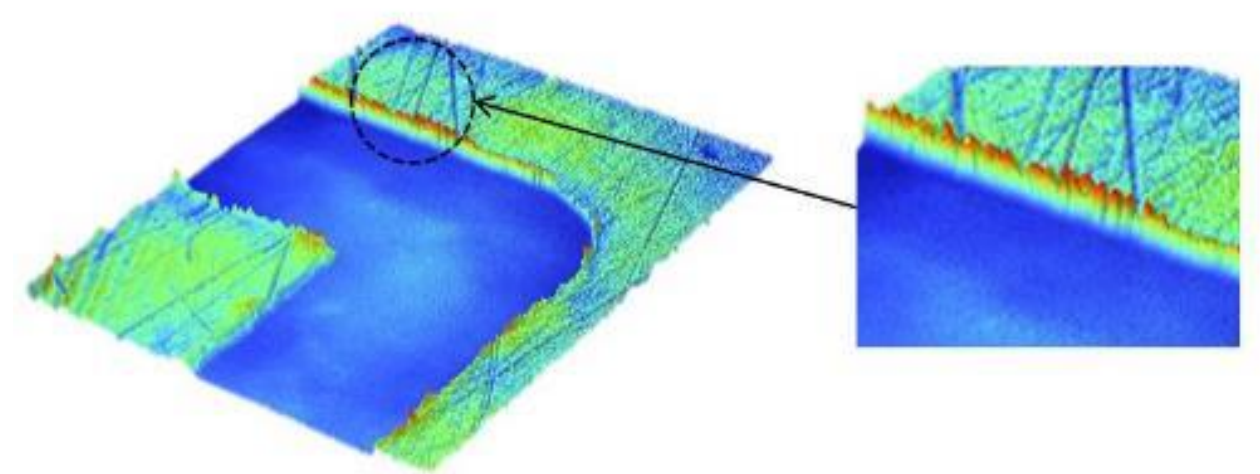


Figure 16: Burrs observed on the PMMA serpentine channels observed in 3D using Veeco non-contact surface profilometer

\subsection{Blood plasma separation using PMMA microfluidic device}
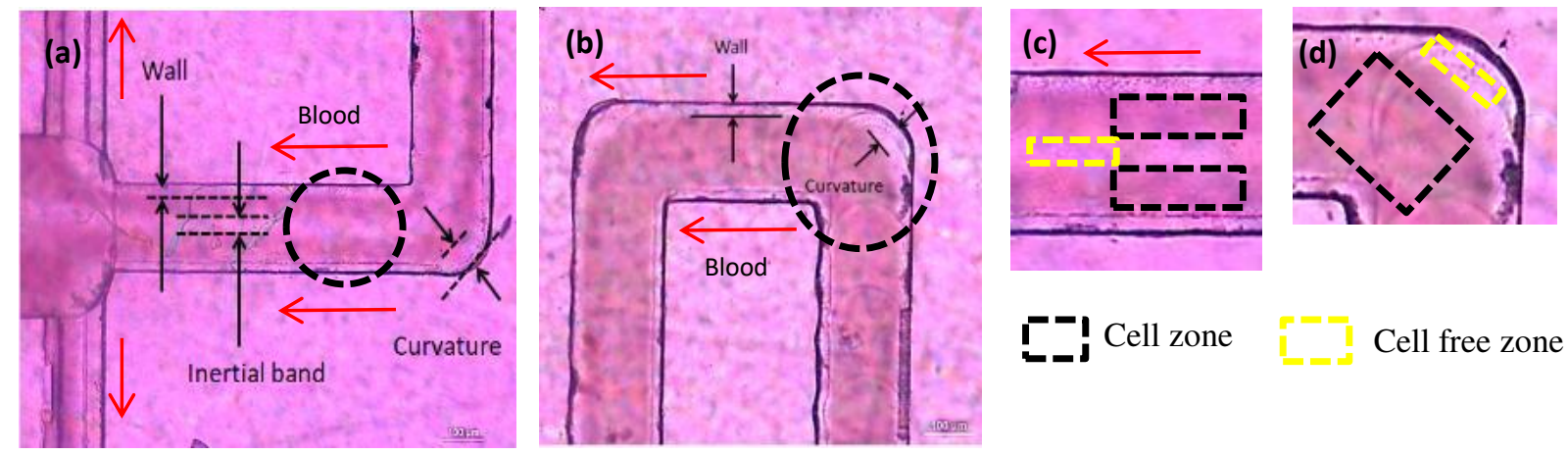

Figure 17: Experimental photograph of the microfluidic device showing inertial focusing in micro-channel for blood diluted to $1: 40$ with $0.9 \% \mathrm{Nacl}$ and with a flow rate of $0.3 \mathrm{ml} / \mathrm{min}$ at a magnification of 10x.(a) at the exit of the channel (b) middle of the channel (c-d) Shows zoomed view of the section

The primary lift forces equilibrate with secondary forces and act on the cells, migrating them across the micro-channels to form cell bands and cell-free regions. Flow experiments were performed at different dilution rates $(1: 40,1: 60,1: 80,1: 100)$ with $0.3 \mathrm{ml} / \mathrm{min}$ flow rate in the microfluidic device fabricated using mechanical micro-milling. Focused cell bands and cell-free regions consecutively appeared in the serpentine channels at a 1:40 dilution rate due to inertial focusing (Figure 17). As the dilution rate increased, cell counts in the middle outlets increased as shown in figure 18. Cell count as shown in table 4 increased from $45 \%$ to $62 \%$ in the middle outlet compared to outlet- 1 and 2 . The particle interactions inhibit the effect of the primary and secondary forces that induce the inertial focusing of the particles. This effect was observed as the dilution rates varied along the $\mathrm{x}$-axis in figure 16 , cell counts in the middle outlet increased while affecting the cell separation at the lower dilution rates. This shows that inertial focusing was more prominent when the cell counts are low at 1:100 dilution rate. To evaluate the repeatability, an experiment at $0.3 \mathrm{ml} / \mathrm{min}$ and $1: 40$ was repeated, and similar results were observed. These experiments show that inertial focusing can be observed in the 
microfluidic devices fabricated using mechanical micro-milling and can be used for the separation of particles from the fluid streams.

\begin{tabular}{|c|c|c|c|c|}
\hline \multicolumn{5}{|c|}{ Table 4: Cell counts at different outlets and dilution rates in the microfluidic device } \\
\hline Dilution rate & Outlet -1 & Outlet- middle & Outlet-2 & Total \\
\hline $\mathbf{1 : 4 0}$ & 64773 & 124420 & 86310 & 275503 \\
\hline $\mathbf{1 : 6 0}$ & 50264 & 112268 & 62415 & 224947 \\
\hline $\mathbf{1 : 8 0}$ & 46864 & 114841 & 58915 & 220620 \\
\hline $\mathbf{1 : 1 0 0}$ & 36048 & 116905 & 34593 & 187546 \\
\hline
\end{tabular}

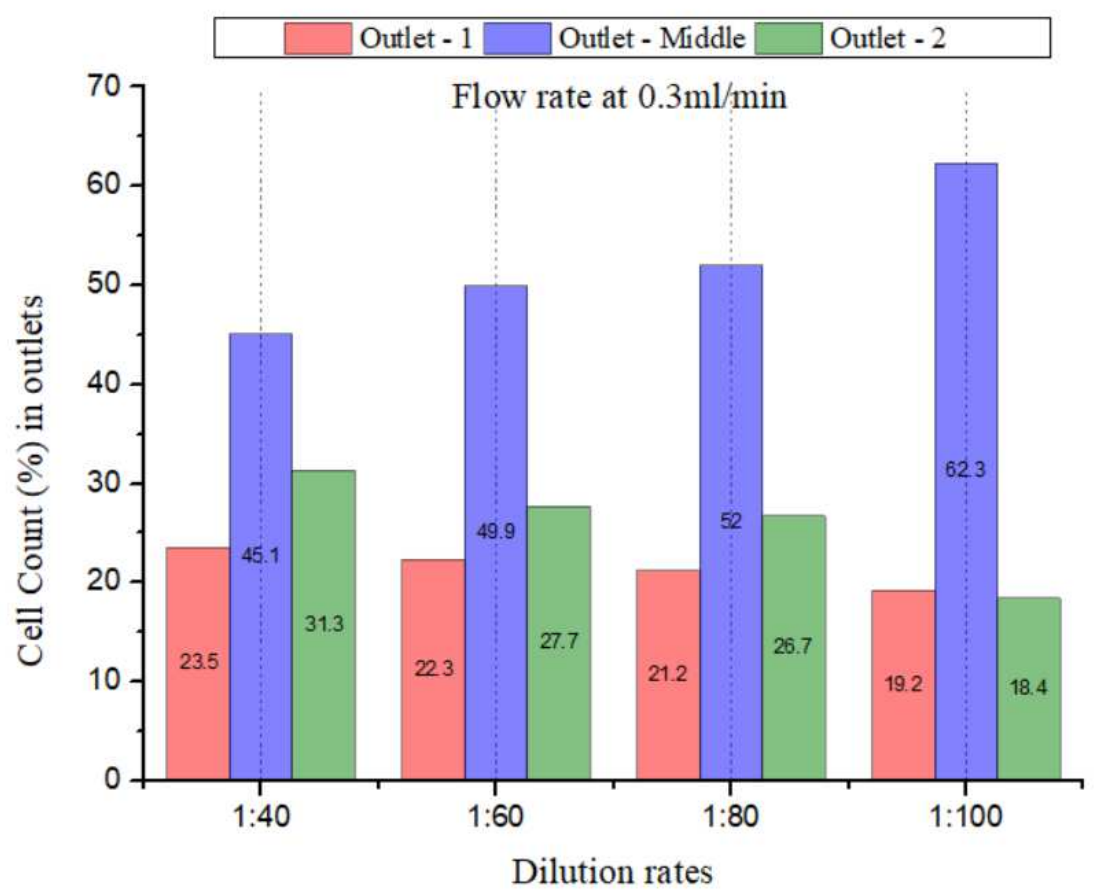

Figure 18: Cell counts in serpentine channels at different dilution rates.

\section{Conclusions:}

In the present work, mechanical micro-milling experiments were carried on PMMA and PC surfaces for understanding the manufacturability of microfluidic devices through direct mechanical micromachining technique. The surface characteristics of the machined surfaces were comprehensively analyzed which includes surface roughness, surface energy, and burr formation. For establishing the 
process capability, the surface energy of the machined surface is later compared with 3D printed, Hot embossed surfaces and other plane surfaces. Furthermore, to validate the proposed fabrication technique, PMMA microfluidic devices with serpentine channels were also fabricated using mechanical micro-milling were examined for blood plasma separation; wherein the experimental results justified the applicability of the proposed methodology for biomedical applications.

1. Machined PMMA surfaces are more hydrophobic compared to machined PC surfaces which makes machined PMMA more suitable for fabricating microfluidic devices. Machined PMMA surfaces with consistent peaks and valleys exhibited less wettability compared to 3D printed, and hotembossed surfaces. Air gaps in the peaks and valleys inherited due to machining might have aided in less wettability on the machined surfaces.

2. A better surface finish using mechanical micro-milling at a lower feed rate $(0.5 \mathrm{~mm} / \mathrm{sec})$ and depthof-cut $(5 \mu \mathrm{m})$ was produced on PMMA and PC surfaces with surface roughness (Ra) of $0.2 \mu \mathrm{m}$. Viscoelasticity, polymer adhesion, and the sudden appearance of peaks and valleys were noted to be the main factors affecting the predictability of the surface finish.

3. Though the burr formation is inevitable while machining polymeric surfaces, microscopic analysis on the machined surfaces showed the occurrence of comparatively smaller burrs on the PMMA surface than that of PC.

4. As the dilution rate increased from 1:40 to 1:100, cell counts increased in the middle outlet of the microfluidic device. At 1:100 dilution, $62 \%$ of the blood cells were collected in the middle outlet while the remaining cells were collected in the other outlets. Cell-free zones and cell bands were observed in the microfluidic channels showing inertial focussing in the devices fabricated using mechanical micro-milling. This proves a successful separation of cells from the fluid flow using serpentine microfluidic channels.

5. Inertial focusing was observed on machined surfaces though there were random peaks and valleys, which shows the applicability of the proposed mechanical micro-milling technique in developing microfluidic devices. 
From the present work, mechanical micromachining proved to be a good alternative to MEMS fabrication techniques for the rapid fabrication of microfluidic devices. Multiple microfluidic devices can be fabricated using mechanical micro-milling by avoiding tool breakage with the proposed machining parameters from this study. Though the major objective of the present work was to investigate the effectiveness of the mechanical micro-milling technique in developing microfluidic devices the current research can be extended by analysing the advanced bonding techniques like solvent bonding, thermal fusion bonding, adhesion, etc., and including other polymeric materials (COC, PEEK, PS, PP, etc.,) for developing higher quality microfluidic devices, and this can be the scope for further extension of the present research work.

\section{References}

1. Waldbaur A, Rapp H, Länge K, Rapp BE. Let there be chip-towards rapid prototyping of microfluidic devices: one-step manufacturing processes. Anal Methods. 2011;3:2681.

2. Whitesides GM. The origins and the future of microfluidics. Nature. 2006;442:368-73.

3. Becker H, Gärtner C. Polymer microfabrication technologies for microfluidic systems. Anal Bioanal Chem. 2008;390:89-111.

4. Nestler J, Morschhauser A, Hiller K, Otto T, Bigot S, Auerswald J, et al. Polymer lab-on-chip systems with integrated electrochemical pumps suitable for large-scale fabrication. Int J Adv Manuf Technol. 2010;47:137-45.

5. Kuo CC, Chiang TS. Development of a precision hot embossing tool with microstructures for microfabrication. Int J Adv Manuf Technol. The International Journal of Advanced Manufacturing Technology; 2017;91:1321-6.

6. Behroodi E, Latifi H, Bagheri Z, Ermis E, Roshani S, Salehi Moghaddam M. A combined 3D printing/CNC micro-milling method to fabricate a large-scale microfluidic device with the small size 3D architectures: an application for tumor spheroid production. Sci Rep [Internet]. Nature Publishing Group UK; 2020;10:1-14. Available from: https://doi.org/10.1038/s41598-020-790155

7. Kummrow A, Theisen J, Frankowski M, Tuchscheerer A, Yildirim H, Brattke K, et al. Microfluidic structures for flow cytometric analysis of hydrodynamically focussed blood cells fabricated by ultraprecision micromachining. Lab Chip. 2009;9:972-81.

8. Wilson ME, Kota N, Kim Y, Wang Y, Stolz DB, Leduc PR, et al. Fabrication of circular microfluidic channels by combining mechanical micromilling and soft lithography. Lab Chip. 2011;11:1550-5.

9. Fredrickson CK, Xia Z, Das C, Ferguson R, Tavares FT, Fan ZH. Effects of Fabrication Process Parameters on the Properties of Cyclic Olefin Copolymer Microfluidic Devices. 2006;15:1060-8.

10. Guckenberger DJ, De Groot TE, Wan AMD, Beebe DJ, Young EWK. Micromilling: A method for ultra-rapid prototyping of plastic microfluidic devices. Lab Chip. Royal Society of Chemistry; 2015;15:2364-78.

11. Srinivasa YV, Shunmugam MS. Development and performance evaluation of miniaturised machine tool (MMT) system. Int J Nanomanuf. 2009;3:133.

12. Srinivasa Y V, Shunmugam MS. Analysis of structural integrity of special purpose miniaturised machine tool and performance evaluation for micro machining applications. 2014;6:366-82.

13. Jagadesh T, Samuel GL. Mechanistic and Finite Element Model for Prediction of Cutting Forces during Micro-Turning of Titanium Alloy. Mach Sci Technol. 2015;19:593-629.

14. Rao S, Shunmugam MS. Analytical Modeling of Micro End-Milling Forces With Edge Radius and Material Strengthening Effects. Mach Sci Technol. 2012;16:205-27. 
15. Srinivasa Y V., Shunmugam MS. Mechanistic model for prediction of cutting forces in micro endmilling and experimental comparison. Int J Mach Tools Manuf [Internet]. Elsevier; 2013;67:1827. Available from: http://dx.doi.org/10.1016/j.ijmachtools.2012.12.004

16. Chen PC, Pan CW, Lee WC, Li KM. An experimental study of micromilling parameters to manufacture microchannels on a PMMA substrate. Int J Adv Manuf Technol. 2014;1-8.

17. Reichenbach IG, Bohley M, Sousa FJP, Aurich JC. Micromachining of PMMA - manufacturing of burr-free structures with single-edge ultra-small micro end mills. Int J Adv Manuf Technol. The International Journal of Advanced Manufacturing Technology; 2018;96:3665-77.

18. Yan Y, Mao Y, Li B, Zhou P. Machinability of the thermoplastic polymers: Peek, pi, and pmma. Polymers (Basel). 2021;13:1-14.

19. Hecht K, Messerschmidt F, Pfeifer P, Dittmeyer R, Kraushaar-Czarnetzki B, Hecht S. Surface roughness of machined microchannels and its effect on multiphase boundary conditions. Chem Eng J [Internet]. Elsevier B.V.; 2013;227:2-12. Available from: http://dx.doi.org/10.1016/j.cej.2012.11.127

20. Hanson C, Hiwase P, Chen X, Jahan MP, Ma J, Arbuckle G. Experimental investigation and numerical simulation of burr formation in micro-milling of polycarbonates. Procedia Manuf [Internet]. Elsevier B.V.; 2019;34:293-304. Available from: https://doi.org/10.1016/j.promfg.2019.06.153

21. Niknam SA, Songmene V. Milling burr formation, modeling and control: A review. Proc Inst Mech Eng Part B J Eng Manuf. 2015;229:893-909.

22. Carr JW, Feger C. Ultraprecision machining of polymers. Precis Eng. 1993;15:221-37.

23. Song K, Lee J, Choi SO, Kim J. Interaction of surface energy components between solid and liquid on wettabilit. Polymers (Basel). 2019;11.

24. Hu Y, Werner C, Li D. Influence of Three-Dimensional Roughness on Pressure-Driven Flow Through Microchannels. J Fluids Eng. 2003;125:871.

25. Kandlikar SG, Schmitt D, Carrano AL, Taylor JB. Characterization of surface roughness effects on pressure drop in single-phase flow in minichannels. Phys Fluids. 2005;17.

26. Di Carlo D, Edd JF, Irimia D, Tompkins RG, Toner M. Equilibrium separation and filtration of particles using differential inertial focusing. Anal Chem. 2008;80:2204-11.

27. Guan G, Wu L, Bhagat AA, Li Z, Chen PCY, Chao S, et al. Spiral microchannel with rectangular and trapezoidal cross-sections for size based particle separation. Sci Rep [Internet]. 2013;3:1475. Available from: http://www.nature.com/srep/2013/130318/srep01475/full/srep01475.html?message-global=remove

28. Zhang J, Yan S, Sluyter R, Li W, Alici G, Nguyen N-T. Inertial particle separation by differential equilibrium positions in a symmetrical serpentine micro-channel. Sci Rep. 2014;4:4527.

29. Zhang J, Li M, Li WH, Alici G. Inertial focusing in a straight channel with asymmetrical expansion-contraction cavity arrays using two secondary flows. J Micromechanics Microengineering [Internet]. 2013;23:85023. Available from: http://iopscience.iop.org/09601317/23/8/085023/article/

30. Bhagat AAS. Inertial microfluidics for particle separation and filtration. Dr thesis. 2009;217-26.

31. Mach AJ, di Carlo D. Continuous scalable blood filtration device using inertial microfluidics. Biotechnol Bioeng. 2010;107:302-11.

32. Zeming KK, Salafi T, Chen C-H, Zhang Y. Asymmetrical Deterministic Lateral Displacement Gaps for Dual Functions of Enhanced Separation and Throughput of Red Blood Cells. Sci Rep [Internet]. Nature Publishing Group; 2016;6:22934. Available from: http://www.nature.com/srep/2016/160310/srep22934/full/srep22934.html

33. Au SH, Edd J, Stoddard AE, Wong KHK, Fachin F, Maheswaran S, et al. Microfluidic isolation of circulating tumor cell clusters by size and asymmetry. Sci Rep. Springer US; 2017;7:1-10.

34. Salafi T, Zhang Y, Zhang Y. A Review on Deterministic Lateral Displacement for Particle Separation and Detection [Internet]. Nano-Micro Lett. Springer Singapore; 2019. Available from: https://doi.org/10.1007/s40820-019-0308-7

35. Zhou J, Papautsky I. Fundamentals of inertial focusing in microchannels. Lab Chip [Internet]. 2013;13:1121-32. Available from: http://www.ncbi.nlm.nih.gov/pubmed/23353899

36. Bhagat AAS, Kuntaegowdanahalli SS, Papautsky I. Continuous particle separation in spiral microchannels using Dean flows and differential migration. Lab Chip [Internet]. 2008;8:1906-14. 
Available from: http://www.ncbi.nlm.nih.gov/pubmed/18941692

37. Yugandhar A, Samuel GL, Lingxue K. Nickel Stamp Fabrication using SU-8 Lithography for Micro Hot-Embossing Serpentine Microfluidic Channels. Int J Precis Technol. 2019;8:298-311. 38. Fowkes FM. Attractive Forces At Interfaces. Ind Eng Chem. 1964;56:40-52.

\section{Acknowledgements}

This work was performed in part at the Melbourne Centre for Nanofabrication (MCN) in the Victorian Node of the Australian National Fabrication Facility (ANFF). The authors are also immensely grateful to Niketh Sasendran, Pavan Kumar Pandit, Prof. Rama S Verma and his students - Raj Pranap Arun, Divya Sivanesan, Bamadeb Patra, and Sudha Varadaraj (Department of Biotechnology, IITM) for sharing their wisdom with us during this research.

\section{Author contributions}

Y.A, G.L.S, and L.K designed the research; Y.A conducted the experiments; G.L.S and L.K analysed and interpreted the data; Y.A, G.L.S, and L.K wrote the manuscript with inputs from all the authors

\section{Competing Interests:}

The authors declare no competing interests.

\section{Availability of data and material}

All the other data required for validation is provided in the manuscript itself. The data that support the findings of this study are available from the corresponding author upon request. The data provided upon request will include images of Surface roughness data, Contact angle measurements, and Surface energy calculations.

\section{Ethics approval and consent to participate}

For the collection of blood samples from volunteers, approval has been obtained from the Institutional Ethical Committee of the Indian Institute of Technology-Madras, with protocol number: IEC/2018/01/GLS/16. Informed and signed consent was obtained and archived for conducting the experiments and publication of results. 